\title{
Valuation of no-negative-equity guarantees with a lower reflecting barrier
}

\author{
R. Guy Thomas \\ School of Mathematics, Statistics and Actuarial Science, University of Kent, Canterbury CT2 7FS, UK \\ E-mail: r.g.thomas@kent.ac.uk
}

(Received 09 February 2020; revised 25 May 2020; accepted 26 May 2020; first published online 10 July 2020)

\begin{abstract}
If the general level of house prices falls a long way, policymakers may introduce new policies which seek to support prices. This paper considers the effect of such interventions on the valuation of no-negative-equity guarantees (NNEG) in equity release mortgages. I model interventions by a reflecting barrier expressed as a fraction of the current level of house prices. Reflection at the barrier is instantaneous, so the no-arbitrage property is preserved, and hence risk-neutral valuation of NNEG is possible. The reflecting barrier can alternatively be justified as a representation of the different economic nature of the underlying housing (and particularly freehold land) assets in NNEG valuations, compared with the underlying equity assets in many other option valuations.
\end{abstract}

Keywords: No-negative-equity guarantee; NNEG; Equity release; Lifetime mortgage; Reverse mortgage; Put option; Reflecting barrier

\section{Introduction}

\subsection{Motivation}

In 2018, I published a blog post on the valuation of no-negative-equity guarantees (NNEG) in equity release mortgages, which included the following passage:

[A] deep and prolonged fall in house prices, with the attendant collapse in mortgage lending, widespread repossessions and distress in the electorate, seems overwhelmingly likely to induce a policymaker response. . In a country with its own currency, the government can (and I believe will) ultimately print money and buy houses. . The activities and statements of central bankers worldwide in relation to asset purchases in recent years provide further general support for this notion of a policy response to deep and prolonged falls in asset (and particularly house) prices. (Thomas, 2018)

Since then several papers and notes on equity release mortgages and NNEG in the specific United Kingdom and Ireland context have been published (e.g. Tunaru \& Quaye, 2019; Jeffery \& Smith, 2019; Buckner \& Dowd, 2019; Dowd et al., 2019; Turnbull, 2019a, 2019b, 2019c). These papers discuss many aspects of equity release mortgages and NNEG valuation. But as far as I am aware, no published work has considered the effect of future policymaker interventions on house prices and hence valuation of NNEG.

This paper models such interventions by means of a lower reflecting barrier under house prices, expressed as a fraction of the level of prices today. Hertrich (2015) and Hertrich \& Zimmermann (2017) give a formula for risk-neutral valuation of a put option in the presence of such a barrier. They consider a currency option, where the barrier represents a floor under the exchange rate

(C) The Author(s) 2020. Published by Cambridge University Press. This is an Open Access article, distributed under the terms of the Creative Commons Attribution licence (http://creativecommons.org/licenses/by/4.0/), which permits unrestricted re-use, distribution, and reproduction in any medium, provided the original work is properly cited. 
which is maintained by a policy of currency intervention by the central bank. Such floors can never be absolute; there is always a risk that the central bank might exhaust its reserves, or change its policy with regard to defending the floor. But there seems little reason to think that a model which simply ignores the policy floor will give a sensible valuation of a currency put. Similarly, interventions in the housing market cannot place a completely firm barrier under prices. But there seems little reason to think that just ignoring the likely political response to large falls in house prices will give a sensible valuation of NNEG.

This paper adapts Hertrich \& Zimmermann's approach to the NNEG context. The key point is that assuming a reflecting barrier even as much as $50 \%$ below today's price level can substantially reduce the value of NNEG. Stated differently: much of the Black-Scholes value of NNEG may derive not from poor scenarios where house prices merely stagnate or fall, but from extreme scenarios where they fall by $50 \%$ or more over the term of the NNEG. If we expect policymakers to intervene in this type of scenario with attempts to support house prices, valuations of NNEG made without consideration of policymaker actions may be overstated.

\subsection{Institutional and regulatory background}

An equity release mortgage is a product whereby an individual borrower typically aged 60 years or more borrows $25 \%-30 \%$ of the valuation of their house from an institutional lender, typically an insurance company. The alternative names "lifetime mortgage" (in the United Kingdom) or "reverse mortgage" (in the United States and Australia) are sometimes used. In the United Kingdom, the most common product design involves a fixed rate of interest charged to the homeowner, but not actually paid. The loan is secured by a first charge on the house. On the borrower's death or any earlier sale of the house (e.g. after the borrower moves into a care home), the loan plus accumulated interest is repayable (typically from the sale proceeds of the house).

In early designs of equity release mortgage in the 1980s, if the loan plus accumulated interest exceeded the sale proceeds of the house, the lender could claim the excess from the borrower's residual estate. This feature came to be perceived as problematic for both borrower and lender. So the product feature of a no-negative-equity guarantee was introduced, and is now a mandatory requirement for members of United Kingdom trade association, the Equity Release Council. The NNEG guarantees that the amount repayable by the borrower (or estate after their death) will not exceed the sale proceeds of the house.

The NNEG allows the borrower to repay the lower of two amounts (the rolled-up loan or the sale proceeds of the house). So the lender's provision of the guarantee is akin to writing a put option on the house price over the term to the borrower's date of death, with a strike price defined as the rolled-up loan at the date of death. Although valuation methods for short-term put options which can be continuously hedged by short sales of the underlying are well known and widely accepted, the NNEG relates to much longer terms, and the underlying asset (the house) cannot readily be sold short. So the application of standard option pricing theory to NNEG valuation is controversial. Starting in 2016, the United Kingdom regulator, the Prudential Regulation Authority PRA), has issued a number of documents touching on NNEG valuation ${ }^{1}$.

The controversy arises principally because the inability to sell short implies that the continuous hedging argument which underlies most justifications of risk-neutral option pricing is not realistic for NNEG. There are some other possible justifications, as outlined in Andreasen et al. (1998) or Wilmott (2009, Chapter 7). But all seem to rely to some degree on assumptions which are not realistic for NNEG. Perhaps the most engaging alternative is that if the underlying asset returns are lognormal, the Black-Scholes formula (or variants thereof) can be inferred without continuous hedging, by assuming a requirement for no arbitrage between prices of puts, calls and forward contracts with common strike prices (Derman \& Taleb, 2005). But even this is not compelling for

\footnotetext{
1 These include PRA Discussion Paper 1/16; Consultation Papers 48/16, 13/18, and 7/19; Policy Statement 19/19; and Supervisory Statement 3/17.
} 
NNEG, because the underlying asset returns are probably not lognormal, and traded puts, calls and forwards on house prices simply do not exist.

Despite these difficulties, a regulator can nevertheless mandate that options should be valued on a risk-neutral basis. This is what the PRA has done for NNEG, at least for the purposes of its Effective Value Test. The Effective Value Test places a limit on the benefit which insurers can obtain by restructuring equity release mortgages to make them eligible assets for the Matching Adjustment $^{2}$ under Solvency II. The Effective Value Test requires that

$$
\left(\begin{array}{l}
\text { value of restructured mortgages } \\
\text { on asset side of balance sheet } \\
+ \\
\text { value of Matching Adjustment } \\
\text { on liability side of balance sheet }
\end{array}\right)<\left(\begin{array}{l}
\text { economic value of } \\
\text { unrestructured mortgages }
\end{array}\right)
$$

where the economic value on the right-hand side must include an allowance for NNEG using a prescribed Black-Scholes type formula (i.e. on a risk-neutral basis) and prescribed minimum parameters (PRA Supervisory Statement 3/17, para 3.20).

In the light of this regulatory requirement, this paper starts from the usual risk-neutral paradigm, and makes the minimum changes necessary to accommodate a reflecting barrier under prices. "Valuation" in this paper means risk-neutral valuation (more often associated with the term "pricing", but in the NNEG context "valuation" tends to be used). I adopt this approach for reasons of consistency and comparability with the regulatory framework. I take the apparent regulatory preference for the principle of risk-neutral valuation as given, and do not further discuss the arguments for or against the principle in the context of long-term unhedgeable options.

This paper focuses on the option pricing aspect of NNEG, in the context of the regulatory background just described. As far as possible, all surrounding detail which is not specific to option valuation is left aside. In practice, a NNEG always has an unknown future term (the time until the borrower's death or earlier repayment of the loan), and so is evaluated by summing the product of option valuation and exit probability over all possible terms. But I ignore this aspect, and instead focus on option valuation over an assumed certain term. I give no consideration to the valuation of the risk-free loan component of equity release, or the calibration of parameters other than volatility and the reflecting barrier. I also do not discuss the restructuring of equity release mortgages into senior and junior tranches as alluded to above.

The rest of this paper is organised as follows. Section 2 summarises past and possible future forms of policy intervention after a large fall in house prices. Section 3 discusses alternative rationales besides policy intervention for assuming a reflecting barrier. Section 4 gives some initial intuition for how a reflecting barrier might affect NNEG values. Section 5 gives a risk-neutral valuation formula for NNEG with a lower reflecting barrier. Section 6 presents examples and sensitivity tests. Section 7 considers what level of barrier to use. Section 8 discusses applications and touches on other approaches to allowing for policymaker actions, notably Economic Scenario Generator models. Section 9 concludes.

\section{Policy Interventions to Support House Prices: Past, Present and Future}

This section outlines the range of policy interventions in the housing market in the United Kingdom that have been observed over the past few decades and the prospects for similar or more extensive interventions after a large fall in prices in future.

\footnotetext{
2 The Matching Adjustment is an increase in the permitted discount rate for liabilities in the Solvency II balance sheet, which is available where the liabilities are backed by long-term illiquid assets with fixed cashflows. Equity release mortgages are contingent on borrower mortality and so do not provide fixed cashflows. But by restructuring them into several tranches, the senior tranches can be assigned fixed cashflows, and so achieve eligibility for the Matching Adjustment.
} 


\subsection{Three types of intervention}

The housing market has been the target of policy intervention for at least as long as any available data series on the general level of prices. At a very general level, owner-occupation is widely perceived as a natural aspiration of many voters and, moreover, one for which the State should provide support. It does so through institutional arrangements, fiscal policies, and monetary policies. These categories are not wholly distinct - the implementation of monetary and fiscal policies necessarily involves institutional arrangements - but they nevertheless provide a convenient taxonomy.

\subsubsection{Institutional arrangements}

Debt finance for the purchase of housing is both more widely available than for the purchase of other assets, and provided at lower interest margins and greater leverage ratios. These differences are facilitated by institutional and regulatory choices. Turner (2016, Chapter 4) discusses the many ways in which banking regulation incentivises banks to prefer lending for the purchase of existing houses rather than other purposes, in particular, the very low regulatory risk weights for loans secured against houses. As a consequence, residential mortgages are more than $50 \%$ of bank lending in the UK, whilst lending to finance nonproperty capital investment is probably less than $15 \%$ (Turner, 2016: 62).

\subsubsection{Fiscal policies}

Fiscal policies can be used to support house prices in many ways. In the United Kingdom, this has included no tax on land values; for owner-occupiers, no tax on capital gains and imputed rents (i.e. the housing services which they consume by living in the house); a low level of property tax (council tax), which is regressive relative to its base (i.e. the more a house is worth, the smaller the proportion of its value that is paid in council tax); and for many years, income tax relief on mortgage interest (albeit this has been phased out for owner-occupiers, and more recently limited for landlords).

Particularly since 2008, the State has also taken a direct role as a provider of various schemes of low-cost finance for house purchase. The Help to Buy scheme, introduced in 2013 and available to all purchasers of newly built houses priced under $£ 600,000$ in England ( $£ 300,000$ in Wales), is the most widely known of these schemes today. It provides an interest-free equity loan for 5 years at a $20 \%$ loan-to-value (LTV) ratio or $40 \%$ in Greater London. The effect of Help to Buy and its lesser known predecessor schemes, at least in part, has been to support house prices ${ }^{3}$. These schemes also expose the State itself to long-term movements in house prices, which may create a new budgetary incentive for intervention after a fall in prices.

\subsubsection{Monetary policies}

Monetary policy measures which can be used to support asset (and particularly house) prices are of two main types: bank-focused and market-focused.

Bank-focused measures primarily relax operating constraints on banks, on the rationale that this will stimulate bank lending and hence activity in the real economy. Any effect on asset prices is secondary and indirect, but can nevertheless be substantial. Bank-focused measures include cuts

\footnotetext{
${ }^{3}$ Carozzi et al. (2020) evaluate the effects of Help to Buy by exploiting the differences in its design in adjacent geographical areas. They find that along the border of the Greater London area, the main effect was to increase prices of new builds just inside the area by about $5 \%$ (compared with new builds just outside the area), with no effect on construction volumes. On the English/Welsh border, where land supply is less constrained, there was some increase in construction volumes, but no effect on prices.
} 
in the short-term official interest rate, open market operations (i.e. purchase of short term government bonds from banks, increasing the monetary base), relaxation of collateral requirements (i.e. the central bank accepts illiquid or low-quality collateral when making loans to banks), and the granting of nonrecourse loans to banks.

Market-focused measures primarily involve purchasing long-duration assets, and so lowering long-term interest rates and raising asset prices. The justification is that this leads to positive confidence and wealth effects, which stimulate activity in the real economy. Market-focused measures are often described as "quantitative easing" (the focus is on increasing the quantity of credit in the economy, rather than reducing the price of that credit, i.e. the interest rate). Quantitative easing was largely unknown before 2008, and originally presented as a short-term response to a banking crisis. But more than a decade later, policymakers increasingly seem to view it as a routine policy tool, with both the quantum of purchases and the range of eligible assets being periodically adjusted in response to macroeconomic events.

\subsection{Potential future policies after a large fall in prices}

The discussion above summarises government interventions in markets for housing and other assets which have been observed in the United Kingdom in relatively "normal" conditions. For NNEG, we are concerned not with "normal" conditions, but with policies which might plausibly be introduced after a large fall in house prices. Here are some forms which such policies could take, both encompassing and extending those previously observed:

- provide subsidies to cover mortgage payments by homeowners in financial distress (e.g. like several new schemes introduced by the Ministry of Housing, Communities and Local Government in 2009: the Mortgage Rescue Scheme, the Repossession Prevention Fund, and the Homeowner Mortgage Support Scheme);

- provide financing on favourable terms for purchases of houses (e.g. low interest, high loanto-value, high loan-to-income, long terms, limited recourse, or interest-free equity loans as in Help to Buy);

- provide new tax breaks (e.g. stamp duty (transaction tax) cuts, deposit grants, reintroduction of mortgage interest relief for owner-occupiers);

- allow individuals early access to their pension funds to fund house purchase (as suggested by the Secretary of State for Housing and Communities in July $2019^{4}$, and the Association of Consulting Actuaries in November 20195);

- provide guarantees of mortgage loans for lenders (e.g. the Help to Buy mortgage guarantee scheme ran from 2013 to 2017 and offered to guarantee up to $£ 12$ bn of loans; under EU rules, these guarantees had to be charged for, but this might not be necessary in future);

- make regulatory changes to encourage or mandate lenders to relax lending criteria, or to exercise forbearance on delinquent loans (e.g. the "Mortgage Preaction Protocol" promulgated by the Ministry of Justice in November 2008);

- buy portfolios of mortgages from lenders, and then relax criteria or exercise forbearance as above;

- nationalise one or more mortgage lenders, and then relax criteria or exercise forbearance as above;

- give temporary guarantees on house prices (cf. the US Treasury's temporary guarantees on money market mutual funds announced on 19 September 2008);

- make direct purchases of houses on the open market.

\footnotetext{
4 'Brokenshire criticised for suggesting first-time buyers dip into pension'. The Guardian, 3 June 2019.

52019 ACA Pensions and Savings Manifesto. www.aca.org.uk, accessed 16 November 2019.
} 


\subsection{The political calculus of interventions}

The political calculus of interventions includes an endowment effect: large falls in prices cause current homeowners to suffer concentrated and actual losses, whilst others (e.g. current renters who might purchase in future) receive only diffuse and hypothetical gains. Consequently, homeowners are not only more numerous than renters, they are also more motivated and organised; they take a greater interest in local planning control, and they are more likely to vote ${ }^{6}$.

Rising financialisation, and in particular the rising financial wealth of the middle class, may have changed the politics of financial crises to favour intervention in asset markets (Chwieroth \& Walter, 2019a, 2019b, 2019c). Many voters now have some awareness of the market value of their pension assets, which was not the case a generation ago, when most pensions were defined benefit. Furthermore, the liberalisation of mortgage lending and other consumer credit means that voters are more financially leveraged than in the past. Hence, the consequences of asset price falls for the electoral prospects of incumbent policymakers may now be larger than in the past.

To summarise this section, there is a long history of policy interventions to support the housing market, and some reasons to think that future policy may be even more responsive to falls in the prices of risk assets, and particularly house prices. The prospect of intervention does not place a completely firm barrier under house prices. Nevertheless, it does limit plausible falls compared with those which might occur in the absence of the intervention, and a reflecting barrier is one way of representing this effect.

\section{Alternative Justifications for a Reflecting Barrier}

In the previous section, the reflecting barrier was conceived as a model of future policymaker intervention after a large fall in house prices. The present section considers some alternative rationales for assuming a floor under house prices, higher than the zero floor which is appropriate for equity in a single company.

Throughout this section, I refer to land rather than houses. Land is to be understood as freehold land. A leasehold potentially introduces different considerations, analogous to the pull-to-par effect for a bond, particularly if the lease is short or the ground rent is high; but houses considered for equity release are usually freehold (or very long leasehold, which is nearly equivalent to freehold). A freehold house price notionally comprises two parts: the land value and the construction costs (indexed to current prices). According to estimates from the Office of National Statistics, $72 \%$ of the value of the total stock of dwellings in the UK is attributable to land values (2015 estimates) $)^{7}$. Similarly, Knoll et al. (2017: 348) estimate that $73 \%$ of the increase in UK house prices between 1950 and 2012 was attributable to land values, and the rest to construction costs. Hence, the considerations for land values in this section can also be expected to be large factors in house prices.

\subsection{Freehold land is an absolute claim, but equity is a residual claim}

The equity of a company incorporated with limited liability is a residual claim: it is the value after all creditor claims, with a lower limit of zero. Even if a company is not leveraged at present, it could easily take on new secured debt in future. If the debt cannot be repaid in line with its terms, the debtholders will take over the firm, and its original equity will then be worth zero. Given this fundamental nature of equity - a residual claim, with a lower limit of zero - a model where the price can go arbitrarily close to (but not below) zero is reasonable.

Freehold land, on the other hand, is an absolute claim, not a residual claim. There is no possibility of it ever being wiped out by unrepayable debt. Freehold land might become worthless

\footnotetext{
${ }^{6}$ According to the polling organisation Ipsos, in the December 2019 election, $70 \%$ of outright owners and $64 \%$ of mortgage holders voted, compared with $51 \%$ and $52 \%$ of private and social housing tenants. https://www.ipsos.com/ipsos-mori/ en-uk/how-britain-voted-2019-election, accessed 22 December 2019.

${ }^{7}$ Data from https://www.ons.gov.uk/economy/nationalaccounts/uksectoraccounts, accessed 26 November 2019.
} 
if it falls into the sea, or suffers some comparable annihilation; but for most plots of land, these circumstances are more remote than equity being wiped out by debt. Freehold land might also become worthless if the legal system through which ownership claims are defined and enforced collapses; but in this state of anarchy, an asset delineated by physical boundaries such as walls would probably retain more value than claims delineated only on paper, such as equities and bonds.

These observations are substantiated by the much greater ease of borrowing secured against a house rather than equity assets. Banks are more willing to lend secured on land rather than equity because of the different nature of the underlying claims. It might be argued that a more proximate driver of banks' preferences is regulation, in particular, the very low risk weights assigned to loans secured on houses compared with those secured on equity assets. This may be true, but it raises the question: why is regulation like that? The answer is the same: the different nature of absolute claims represented by land values versus residual claims represented by equity values makes the former more suitable as collateral.

\subsection{The supply of new land is less elastic than the supply of new equity}

When investor demand for equity in a particular industry increases, the price of equity rises. This tends to induce a supply response: it becomes more attractive for private companies to list, or for entrepreneurs to enter the industry and issue new equity. This supply response is straightforward and elastic, and it limits the rise in the price of equity in response to the increased demand.

On the other hand, if the demand for land for house-building increases, the possibilities for a supply response are less straightforward. New land for house-building can be created only by re-zoning the planning status of agricultural or industrial land. But this re-zoning is heavily constrained by political calculus: the potential losses from re-zoning (to existing homeowners in a locality) are concentrated, but the potential benefits (to hypothetical purchasers or tenants of houses not yet built) are dispersed. The creation of new residential land is, therefore, constrained and slow compared with the creation of new equity, which represents the everyday functioning of capital markets.

\subsection{Land in good neighbourhoods is a positional good}

Land in good neighbourhoods is a positional good. That is, the utility derived from the good depends on how much of it one possesses relative to how much others possess. If you possess a positional good, you receive positive utility, and those who do not possess it receive negative utility as a consequence of your possession of it; a positional good is essentially zero-sum. Land as space (a material good) is physically scarce, but land in whatever are deemed to be good neighbourhoods (a positional good) is socially scarce.

As society becomes richer, basic needs for food and shelter can be satisfied by a smaller fraction of income. Also, the cost of producing many goods tends to fall in real terms, because of technological advances, and competition between suppliers ensures that these cost reductions are passed on in the prices of finished goods. But positional goods cannot be manufactured; they derive from social comparison, and so the combination of technological advance and supplier competition has no effect on their prices. Therefore, the fraction of society's aggregate income spent on competing for positional goods tends to rise with increasing wealth (Turner, 2016: 70; Stiglitz, 2015: 4). This social competition tends to underpin land values in good neighbourhoods.

Each of the above points - the absolute nature of freehold claims, the inelasticity of supply of land, and the positional nature of land - may substantiate a floor for land values (and hence house prices) somewhere above the floor of zero which seems appropriate for equity in a single company. Fundamentally, freehold land is a different type of asset from equity, with a priori reasons for less density in the lower tail of long-term returns. None of the points is fully convincing on its own, 
but in combination, they may be persuasive, particularly if viewed through the lens of investment epistemology rather than mathematical epistemology. By investment epistemology, I mean the view that it is better to have several weak (but at least partially independent) reasons for believing something, rather than one purported rigorous "proof". Rigour seldom changes anyone's mind about anything important in economics, and nor should it, because all rigour is local.

\section{Intuition for NNEG Value in the Presence of a Reflecting Barrier}

In this section, I give some initial intuition on how a reflecting barrier affects the value of NNEG.

\subsection{Simple example}

I start with a simple illustrative example. I ignore mortality and other decrements (which are not salient to the option pricing aspects of NNEG) and instead assume a NNEG written today for a 65 -year-old customer has a term certain of 25 years. Other assumptions are

- house spot price, $S=1$ (equivalently: we work in units of the spot house price);

- initial loan-to-value ratio $=0.3$;

- roll-up rate $=4 \%$ (so strike price of option, $X=0.3 \times 1.04^{25}=0.8$ );

- risk-free rate, $r=1.5 \%$;

- deferment rate, $q=1 \%$; and

- house price volatility, $\sigma=13 \%$.

Some points in these assumptions merit further explanation. The deferment rate, a term originated by the PRA, is the discount rate which when applied to the spot price of a house gives the deferment price, that is, the price payable now for possession of the house at the end of the term. In other option pricing literature, the deferment price is normally called the prepaid forward price. The initial loan-to-value of 0.3 , roll-up rate of $4 \%$ and option term of 25 years are convenient examples inspired by Turnbull (2019a), although clearly the term, in particular, will vary widely across the different years summed for even a single customer's NNEG. The house price volatility of $13 \%$ and deferment rate of $1 \%$ correspond to the minimum parameters suggested by the PRA in Consultation Paper 13/18, before the PRA moved to periodic updating of these parameters.

On the above assumptions, the Black-Scholes style price ${ }^{8}$ for a put option is 0.077 , and a call option is 0.306 . Buying a call and writing a put involves an outlay of $C-P=0.229$. By put-call parity, it follows that we pay a premium of 0.229 now to enter a forward contract to buy at 0.8 after 25 years ${ }^{9}$.

The premium to enter a forward can equivalently be calculated as the present value of the forward price (i.e. the price agreed today for payment after 25 years to receive the asset at that time), less the present value of our actual obligation to pay 0.8 after 25 years; or symbolically, $e^{-r T}\left[S e^{(r-q) T}-0.8 S\right]=0.229$ as expected.

The equivalence just noted, $(\mathrm{C}-P)=$ (premium to enter a forward), is known as the "standard put-call parity". It can be shown that using risk-neutral prices for both puts and calls is mutually implicative with the standard put-call parity (Derman \& Taleb, 2005). The "standard" qualifier is necessary in this paper because we shall find that in the presence of the reflecting barrier, the mutual implication between risk-neutral pricing and put-call parity breaks down. The next section starts to give some intuition for this.

${ }^{8}$ The price is actually calculated using the Black ' 76 formula, equation (9) later in the paper.

${ }^{9}$ As a reminder for the reader: put-call parity says that if we buy a call and write a put with the same maturity $T$ and strike price $X$, this is economically equivalent to entering into a forward contract to purchase the stock by paying $X$ at time $T$. This is because if the stock price ends up above $X$, we exercise our call; if the stock price ends up below $X$, the put is exercised against us; so we are exposed to all the upside and downside at expiry, and we are committed to paying $X$ at expiry. So the net cashflow for buying the call and writing the put must be equivalent to the premium for entering into the forward contract. 


\subsection{Introducing a reflecting barrier}

Now assume a new commitment from a policymaker to intervene to support the price at a lower barrier $b=0.8$ (the same as the strike, i.e. the rolled-up loan for our example NNEG). This means that if the price falls to the level of the barrier, the policymaker makes a small purchase so that price reflects instantaneously off the barrier, spending no finite time there. Assume the commitment is fully credible to all. What difference does this make?

- Market participants recognise the new commitment to intervention, so the spot price rises, say from $S$ to $S^{\prime}$. The forward price rises in the same proportion, from $S e^{(r-q) T}$ to $S^{\prime} e^{(r-q) T}$. This is because interventions move spot and forward in the same way, and the cash-andcarry arbitrage which determines forward pricing operates in the same way as before. So the forward price expressed in a numeraire of the (new) observed spot price remains 0.229 (but the forward price expressed in $\mathfrak{E}$ is higher than before).

- The put now costs us nothing to buy, because the fully credible barrier means the price can never go below the strike. Note that Black-Scholes gives a different (higher) price, which is clearly not sensible.

- Buying the call, on its own, now appears equivalent to entering a forward contract to buy at 0.8 . This is because the call now must have a positive payoff (because the barrier prevents the price ever going below 0.8 ), and so we are certain to exercise it. So applying the logic of standard put-call parity suggests that the price of a call should equal the 0.229 premium to enter a forward (but we shall see later that this is not the only plausible concept of price for a call). Note that Black-Scholes again gives a different (higher) price.

- As a consequence of the previous two points, the link between using Black-Scholes prices for both puts and calls and the standard put-call parity seems to be broken. This breakage is unsurprising for standard Black-Scholes (which clearly has no term for barrier), but we shall see later that the breakage is more fundamental, and persists even when we construct a riskneutral option price which allows for the barrier. One can start to gain some intuition for this breakage from the next two points.

- First, suppose we know nothing of risk-neutral valuation, and instead attempt to value options by the actuarial expectation of their payoffs. In evaluating the expectations, what assumptions should we use for the discount rate, and growth rate of the underlying asset? Without the barrier, continuous variation in these assumptions will lead to continuous variation in the prices of each of puts and calls. It turns out that the risk-neutral rate (for both discount and growth) is the only assumption that will satisfy the standard put-call parity for all possible strikes. In this sense, risk-neutral pricing and the standard put-call parity are normally mutually implicative (Derman \& Taleb, 2005).

Second, introduce a reflecting barrier equal to the strike. Then the logic in the previous point breaks down: the price can never go below the barrier, so a put is now clearly worth zero for any assumed rate of underlying asset growth! This apparent indeterminacy suggests that the usual link between a specific assumed rate of growth (the risk-neutral rate) and put-call parity no longer works.

In summary, ordinary Black-Scholes does not give sensible valuations in the presence of a reflecting barrier, and there seem to be complications with put-call parity.

\subsection{Bull put spread as an upper bound}

A bull put spread is a well-known option trade, which can be used to get an upper bound for the value of a put in the presence of a reflecting barrier. The trade involves selling a put with a high strike (in our case, the NNEG strike $X$, i.e. the rolled-up loan), and buying a put with a low strike (in our case $b$, the level of the barrier). The payoff diagram for the trade is shown in Figure 1.P(X) is a put with strike $X$ and $P(b)$ is a put with strike $b$. Note that the maximum loss we might incur 


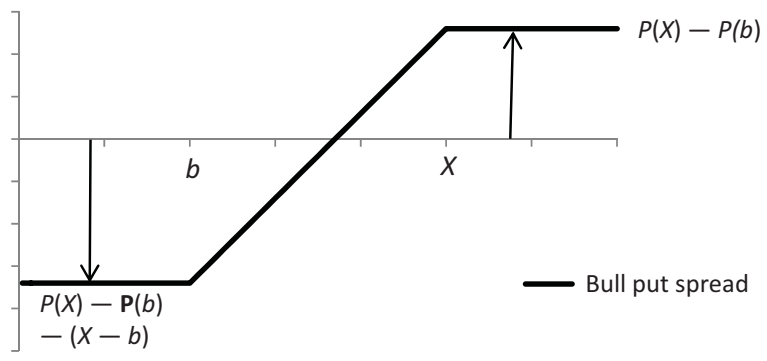

Figure 1. Payoff diagram for bull put spread.

at maturity is $(X-b)$, but the price diffusion on the path to maturity can go below $b$ (and may be below $b$ at maturity). With a reflecting barrier, the maximum loss is the same, but the diffusion is modified so that it can never go below $b$. Intuitively, this must reduce the value of the put with barrier compared with the bull put spread, because in scenarios where the diffusion previously went below $b$, it is now reflected off the barrier. So the bull put spread $P(X)-P(b)$ represents an upper bound on the value of NNEG with a reflecting barrier.

\section{Risk-Neutral Valuation Formula for NNEG in the Presence of a Reflecting Barrier}

This section gives a formula to price a put option with a reflecting barrier under the spot price, using the risk-neutral pricing paradigm. Hertrich \& Zimmermann $(2015,2017)$ give a formula for a put on an exchange rate with a reflecting barrier. Their formula involves two risk-free interest rates, one in the transaction currency and one in the settlement currency. The adaptation to the NNEG context involves replacing the settlement currency risk-free rate with the deferment rate, that is, the discount rate which when applied to the spot price gives the price payable now for possession of the house at the end of a term. The adaptation can be intuitively understood by observing the following correspondence:

- The exchange rate is the number of units of the transaction currency (which earns the riskfree rate) required to buy one unit of the foreign currency (which earns the foreign risk-free rate).

- The house price is the number of units of the transaction currency (which earns the risk-free rate) required to buy one unit of housing (which earns a net rental yield, assumed equivalent to the deferment rate).

The equivalence just assumed between net rental yield and deferment rate depends on the assumption that both the spot price and the deferment price are fully determined by a "dividend discount" model applied to rents, with the same effective discount rate used by both spot and deferment purchasers. Since the spot price is determined primarily by owner-occupiers, but the (hypothetical) deferment price would be determined by a quite different type of purchaser - those interested in deferred possession - the two discount rates might not be the same. Hence, the deferment rate may not be equivalent to net rental yield. Indeed, the PRA's prescribed minimum deferment rate is conceived as the long-term real risk-free rate, plus a risk premium required by investors in housing, less expected real capital growth, with the latter two items assumed stable over time (PRA Policy Statement 19/19 para 2.6(ii)). If this concept of deferment rate is preferred, the adaptation of the currency option formula can alternatively be understood by observing the following correspondence:

- The foreign currency risk-free rate is the rate which gives the prepaid forward price of 1 unit of foreign currency (expressed in units of the foreign currency today). 
- The deferment rate is the rate which gives the prepaid forward price of 1 unit of housing (expressed in units of housing today, which are equivalent to units of currency, because house prices are always denominated in currency).

I now give a brief sketch of the formal method of derivation. For technical details, see Appendix $A$, and the papers referenced therein.

We start with a standard geometric Brownian motion for the price process. We then impose a reflecting barrier somewhere below the lower of the spot price and the strike price (i.e. $b<\min (S$, $X)$ ). The strike can be either lower or higher than the spot price, i.e. in or out of the money. The spot price evolves as a geometric Brownian motion (GBM), except that if the spot price hits the barrier from above, reflection occurs instantaneously, and with infinitesimal size. We can think of this as the State making a small purchase which prevents the price falling below the barrier.

The instantaneous nature of the reflection means that the price does not spend any finite time at the barrier, so no arbitrage opportunities are created (we can never buy at the barrier with certainty of a price rise). The absence of arbitrage in our model of the asset returns ensures that an equivalent martingale measure exists; in other words, a risk-neutralised version of the density for the asset price at maturity exists. The risk-neutralised density for this "reflected geometric Brownian motion" (RGBM) has previously been published. So we can price the put option with reflecting barrier by integrating its intrinsic value over this risk-neutral density, that is, we integrate

$$
P_{B}(X)=e^{-r T} \int_{b}^{X}\left(X-S_{T}\right) f\left(S_{T}\right) d S_{T}
$$

The resulting risk-neutral valuation formula for a put $P_{B}$ with a reflecting barrier at $b<$ $\min (\mathrm{S}, X)$ is

$$
\begin{aligned}
P_{B}(X \mid S, r, q, \sigma, T, b) & \\
= & X \mathrm{e}^{-r T} \Phi\left(-z_{1}+\sigma \sqrt{T}\right)-S e^{-q T} \Phi\left(-z_{1}\right) \\
& -b \mathrm{e}^{-r T} \Phi\left(-z_{3}+\sigma \sqrt{T}\right)+S e^{-q T} \Phi\left(-z_{3}\right) \\
& +\frac{1}{\theta}\left\{\begin{array}{l}
b e^{-r T} \Phi\left(-z_{3}+\sigma \sqrt{T}\right) \\
-S e^{-q T}\left(\frac{b}{S}\right)^{1+\theta}\left[\Phi\left(z_{4}\right)-\Phi\left(z_{2}\right)\right] \\
-X e^{-r T}\left(\frac{X}{b}\right)^{\theta-1} \Phi\left(z_{2}-\theta \sigma \sqrt{T}\right)
\end{array}\right\}
\end{aligned}
$$

which can be understood as

$$
P_{B}(X)=P(X)-P(b)+\text { Adjustment }
$$

where the two $P$ on the right-hand side are the Black ' 76 prices for puts with strikes $X$ and $b$ (i.e. calculated using equation (9)), and Adjustment is the $1 / \theta$ term with

$X=$ strike price (for NNEG, the projected rolled-up loan amount at maturity), $S=$ current spot price, $T=$ term, $b=$ barrier price, $r=$ risk-free rate ${ }^{10}, q=$ deferment rate, $\sigma=$ volatility, $\Phi()=$. the standard normal cumulative distribution function

and

$$
z_{1}=\frac{1}{\sigma \sqrt{T}}\left[\ln \left(\frac{S}{X}\right)+\left(r-q+\frac{\sigma^{2}}{2}\right) T\right]
$$

${ }^{10}$ In its Effective Value Test, the PRA prescribes $r$ as "the published Solvency II basis risk-free rate for maturity $T$, adjusted for use on a continuously-compounded basis" (SS 3/17, para 3.20). There may be a case for discounting at a higher rate including an illiquidity premium to reflect the illiquid nature of NNEG, but I leave that aside in this paper. 


$$
\begin{aligned}
& z_{2}=\frac{1}{\sigma \sqrt{T}}\left[\ln \left(\frac{b^{2}}{X S}\right)+\left(r-q+\frac{\sigma^{2}}{2}\right) T\right] \\
& z_{3}=\frac{1}{\sigma \sqrt{T}}\left[\ln \left(\frac{S}{b}\right)+\left(r-q+\frac{\sigma^{2}}{2}\right) T\right] \\
& z_{4}=\frac{1}{\sigma \sqrt{T}}\left[\ln \left(\frac{b}{S}\right)+\left(r-q+\frac{\sigma^{2}}{2}\right) T\right] \\
& \theta=2 \frac{(r-q)}{\sigma^{2}}
\end{aligned}
$$

For a zero barrier $(b=0)$, the formula reduces to the standard Black '76 formula (Black, 1976)

$$
P(X \mid S, r, q, \sigma, T)=\mathrm{e}^{-r T}\left[X \Phi\left(-z_{1}+\sigma \sqrt{T}\right)-S e^{(r-q) T} \Phi\left(-z_{1}\right)\right]
$$

and for a barrier equal to the strike $(b=X)$, the formula gives a value of 0 . This confirms that the formula works as expected at both extremes.

It is important to note that the formula in equation (2) applies only for a barrier less than the lower of the spot price and strike price $(b<\min (\mathrm{S}, X))$. The requirement $b<S$ is straightforward and can be ensured by coding a cap of $S$ on the input parameter $b$. The requirement $b<X$ requires some care, because the barrier is fixed for valuing options over all terms, but a NNEG is evaluated by summing a series of "mini-NNEGs" over terms of $1,2,3, \ldots$ years; so for low loan-to-value cases, the shorter terms may well have $b>X$. For these terms, the "mini-NNEG" is clearly worth zero, but naïve application of the formula will wrongly give a positive value. So as a precaution in any practical implementation, the formula should be embedded in a conditional statement which returns the correct zero value if $b>X$.

Note that the $P(X)-P(b)$ part of the formula is the premium we receive to enter a bull put spread as described in section 4.3. As discussed in that section, this represents an upper bound on the value of NNEG with a reflecting barrier. So the Adjustment is zero for $b=0$ and $b=X$, and negative everywhere in between. For the examples in this paper, the magnitude of the Adjustment is largest for a barrier somewhere above $0.5 \times$ the strike. At this level of barrier and with other parameters as in the example in section 4.1, the Adjustment is up to half the value of the bull put spread, so there is a substantial difference.

Although the formula looks complicated compared with Black '76, the complication is algebraic rather than parametric: there is only a single extra parameter, the barrier level $b$. The value of the single parameter can be thought of as a shorthand for different strength of beliefs about the prospects for intervention, or about the different nature of housing assets compared with equity assets as discussed in section 3 above. Whilst the barrier feature is an artificial model of intervention, it is also easy to describe and explain, including for audiences who may not understand all the niceties of option pricing.

Note that as with Black '76, the formula does not include any term relating to the expected rate of growth of house prices. The price process is modified at the barrier, but otherwise, it has the same drift as ordinary GBM, and this drift is removed by risk-neutralisation.

The formula gives a risk-neutral price for a put. The risk-neutral price of a call with the same strike $X$ would normally be immediately inferred from put-call parity (i.e. call $=$ forward + put). However, some care is needed with this in the presence of the reflecting barrier. Contrary to the usual pattern, the call price inferred in this way is not the same as a risk-neutral price for a call. Since we are mainly interested in the price of a put for NNEG, a pragmatic solution is to adopt 


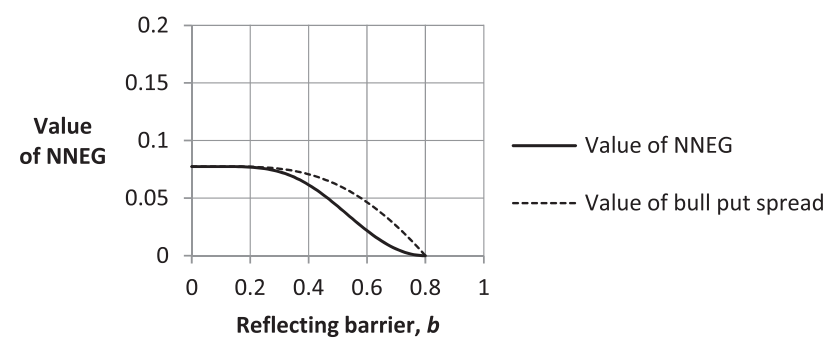

Figure 2. NNEG with reflecting barrier compared with a bull put spread.

the risk-neutral price for the put, and note the need for caution about inferring a price for a call. Fortunately, we do not normally require call prices in the context of NNEG, nor are there any market prices for forwards and calls with which we need to ensure consistency. The technical point is discussed further in Appendix B.

One interpretation of a risk-neutral option price is that it represents the cost of replicating the payoffs of the option by continuous hedging. Although we cannot in practice do this for NNEG (because houses cannot readily be sold short), it is interesting that the hedging recipe turns out to be simpler than casual inspection of the put formula in equation (2) might suggest. This is covered in Appendix C.

The formula can be reconciled to previous work in the actuarial literature, in particular, the Gerber \& Pafumi (2000) and Imai \& Boyle (2001) formula for the value of a dynamic guarantee on an investment fund. This is covered in Appendix D.

\section{Examples and Sensitivity Tests}

\subsection{Examples}

Figure 2 illustrates the example NNEG specified in section 4.1, for all possible levels of the reflecting barrier (recall that the option strike is $0.3 \times 1.04^{25}=0.8$, so any nontrivial barrier must be below 0.8 ). The solid curve shows the value of NNEG on the stated parameters (notably deferment $1 \%$, volatility $13 \%$ ). The dashed curve shows the corresponding bull put spread. The value of NNEG is equal to the bull put spread at $b=0$ and $b=X$, and less everywhere in between, as expected.

It is important to remember that in all our formulae and graphs, the numeraire is the observed spot house price, given the barrier level in force. As noted in section 4.2, a rise in the level of the barrier generally assumed by market participants will lead to a rise in the observed spot price, but all NNEG values are then expressed in units of the new observed spot price. So we should be cautious about applying the formula with the old spot house price to assess the effect of introducing or changing a barrier. In the NNEG case, this distinction does not matter, because we are not contemplating the "introduction" of a barrier; the barrier (if it exists) has always been there, or at least has been there for a very long time. But the distinction may be important in other applications.

In the remainder of this paper, I adopt the parameters from section 4.1 as the central assumptions (i.e. corresponding to the solid curve in Figure 2), and show the effect of equal step changes up and down for each key parameter around these central assumptions.

Figure 3 shows the sensitivity when volatility is flexed up or down $5 \%$. Note that for lower levels of volatility, the curve is nearly flat over a wider range. This is because, for lower levels of volatility, the risk-neutral density has less mass at low prices, so that it makes almost no difference whether the barrier is at 0 or 0.5 ; only a barrier quite close to the strike makes a difference.

The ordering of the three curves reverses towards the right end of the three curves in Figure 3 (albeit this cannot be seen clearly given the scale of the graph). In other words, for a barrier very close to the strike, a rise in volatility slightly reduces the value of a put. Intuitively, this is because 


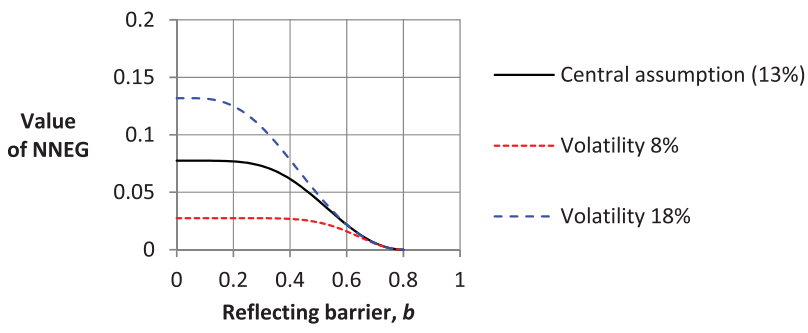

Figure 3. Sensitivity to volatility.

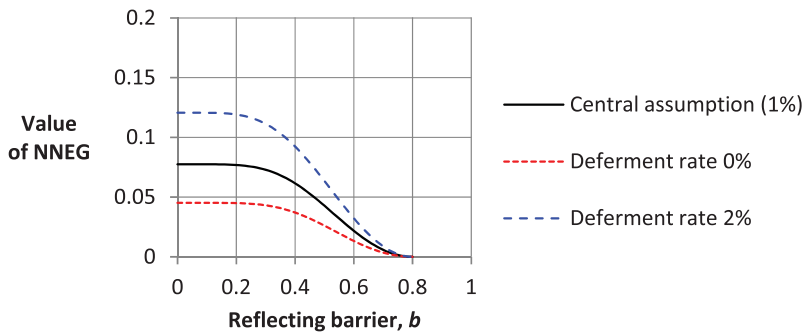

Figure 4. Sensitivity to deferment rate.

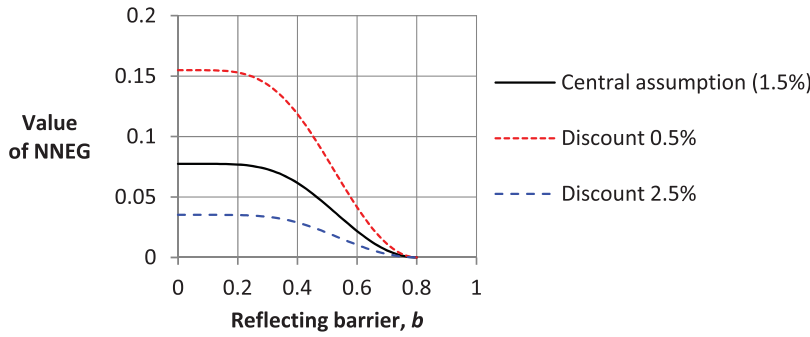

Figure 5. Sensitivity to discount rate.

when the barrier is very close to the strike, a rise in volatility cannot materially increase the intrinsic value of the option, and does make it more likely that the spot price will end up just above rather than just below the strike (meaning that the option expires worthless). But this curious effect is mainly of theoretical interest, because a barrier very close to the strike makes the option nearly worthless anyway. This effect applies only for a put option; for a call option, the effect of volatility is monotonically positive, as expected.

Figure 4 shows the sensitivity when the deferment rate is flexed up or down $1 \%$. A higher deferment rate increases the value of NNEG.

Figure 5 shows the sensitivity when the discount rate (risk-free rate) is flexed up or down $1 \%$. A higher discount rate reduces the value of NNEG. The shape and dispersion of the lines in this graph are very similar to the previous graph for the deferment rate, but the blue and red lines are interchanged. This is because deferment rate and discount rate have analogous but opposite effects on the value of NNEG. Increasing the deferment rate reduces the "deferment price" input into the formula; increasing the discount rate applies more discounting to the option payoff.

Figure 6 shows the sensitivity when the roll-up rate on the NNEG is flexed up or down 1.5\%. Increasing the roll-up rate increases the value of NNEG. This is because given the assumed $30 \%$ initial loan-to-value and 25 -year term, roll-up rates of $2.5 \%, 4 \%$ and $5.5 \%$ correspond to strikes of $0.556,0.800$ and 1.144 , respectively. For the strike of 1.144 , the curve terminates at 1 because the maximum feasible barrier is the current spot price of 1 . Note that a barrier of say 0.6 reduces 


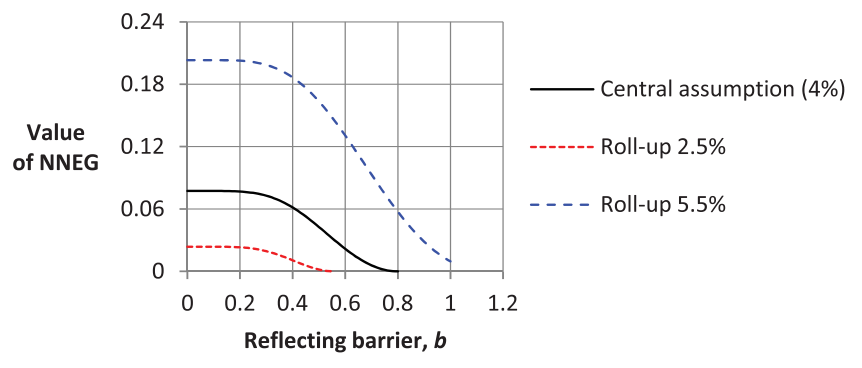

Figure 6. Sensitivity to roll-up rate.

the value of NNEG by $100 \%$ for $2.5 \%$ roll-up (because the loan never rises above the barrier), $70 \%$ for $4 \%$ roll-up, and $35 \%$ for $5.5 \%$ roll-up. In other words, the fractional reduction (but not the absolute reduction) is larger for lower roll-up rates.

Flexing the term certain or initial loan-to-value of the NNEG unsurprisingly has similar effects to flexing the roll-up rate (recall that strike $=$ initial loan-to-value times $(1+\text { roll-up rate })^{T}$ ), so no separate graphs are shown for these. The variations which give equivalent effects to those shown for $2.5 \%$ and $5.5 \%$ in Figure 6 are term certain flexed to 16 years and 34 years (from central assumption of 25 years) and initial loan-to-value flexed to 0.21 and 0.43 (from central assumption of 0.30 ).

\subsection{Comparison with "real-world" valuations}

A common but disputed approach to NNEG valuation in practice has been to make an ad hoc adjustment to the Black '76 formula in equation (9), replacing the forward price of the house with a projected price of the house at maturity. In other words, the forward rate $(r-q)$ is replaced by an assumed house price growth rate (say $g$ ). The assumed $g$ is invariably higher than $(r-q$ ), and so this gives a lower answer than equation (9). Furthermore, the assumed $g$ is also usually higher than the risk-free rate $r$ on its own, and so implies a negative input for the deferment rate $q$ in equation (9). This is sometimes called the "real-world" method (e.g. Hosty et al., 2008, paragraph 7.7.4), and it produces values dramatically lower than Black'76. How does the barrier model compare?

In Table 1, the left-hand side shows NNEG values using the barrier model, for a range of barrier levels. The right-hand side shows NNEG values using the "real-world" method, for a range of house price growth rates. On both sides, all other parameters are set to the same central assumptions as in section 4.1 .

The comparison between the two methods is more fully illustrated in Figure 7. The blue solid curve represents values from the barrier model, with the variable barrier level on the lower axis. The red dashed curve represents values from the "real-world" model, with the variable house price growth rate along the upper axis. The blue shaded area indicates a range of what might be regarded as plausible assumptions for the barrier, say 0.3 to 0.6 . The red shaded area indicates a range of what might be regarded as plausible "real world" assumptions for house price growth, say $2 \%$ to $4 \%$. The overlap of the two shaded areas is small, indicating that the barrier method produces higher valuations than the "real-world" method for most plausible assumptions. This comparison will apply a fortiori for any higher assumed strike than 0.8 (with a higher strike, the effect of a barrier at any given level diminishes, so the NNEG value from the barrier model rises closer to the Black' 76 value).

Notwithstanding this comparison, it is important to note that the rationales of the barrier and "real-world" methods are different. The barrier method uses a reflecting barrier, which implies a different stochastic process for the price, but otherwise applies the standard principles of riskneutral valuation. The "real-world" method uses an ad hoc modification of Black '76, for which it may be difficult to provide specific justification. The difference in rationales is reflected in the 
Table 1. Comparison of barrier model (strike price $=0.8$ ) with "real-world" model

\begin{tabular}{cccc}
\hline \multicolumn{2}{c}{ Barrier model } & \multicolumn{2}{c}{ "Real-world" model } \\
\hline Barrier level & NNEG value & House price growth (\%) & NNEG value \\
\hdashline 0 & 0.0774 & 0 & 0.0977 \\
\hline 0.2 & 0.0768 & 1 & 0.0599 \\
\hline 0.4 & 0.0616 & 2 & 0.0332 \\
\hdashline 0.6 & 0.0217 & 3 & 0.0166 \\
\hdashline 0.8 & 0 & 4 & 0.0073 \\
\hline
\end{tabular}

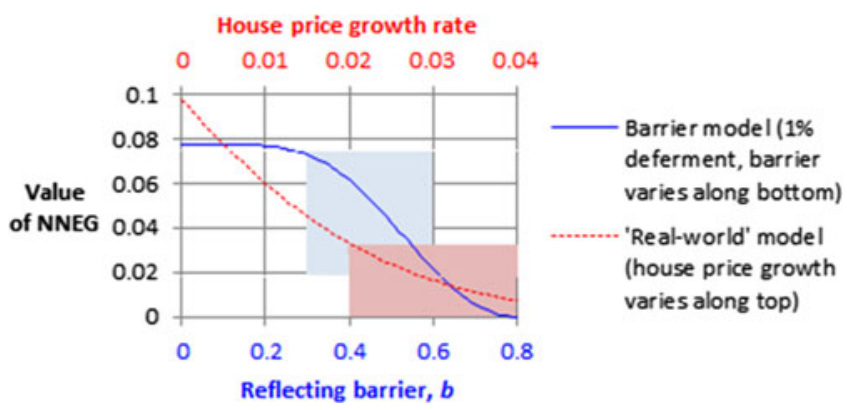

Figure 7. Comparison of barrier model (variable barrier, bottom axis) with "real-world" model (variable house price growth, top axis).

different shapes of the curves in Figure 7. In the "real-world" method, an increase in the assumed house price growth rate gives a convex reduction in the value of NNEG, for all levels of the house price growth rate. In the barrier method, the effect of an increase in the assumed barrier level depends on how close the barrier already is to the strike.

The barrier model implies a zero valuation for any NNEG where the rolled-up loan at maturity is less than the level of the barrier (albeit this zero value needs to be coded by embedding the valuation formula in a conditional statement, as mentioned in section 5). More generally, the barrier model's valuation as a multiple of a corresponding "real-world" valuation will tend to be higher for higher roll-up rates, higher initial loan-to-value ratios, and longer terms to maturity. For roll-up rates, the pattern is illustrated in Figure 8. The greater separation of the red and blue curves as we move up the graph shows that as we increase the roll-up rate, the barrier valuation gets further above the "real-world" valuation. Specifically, the top pair of red and blue curves shows that for $5.5 \%$ roll-up, any level of barrier up to about 0.7 gives a higher valuation than the real-world method with typical house price growth assumptions (say $2 \%-4 \%$ ). On the other hand, the bottom pair of red and blue curves shows that for $2.5 \%$ roll-up, any barrier above 0.42 gives a lower valuation than the "real-world" method with house price growth of $2 \%$; and any barrier above 0.55 gives a zero valuation (because the rolled-up loan never exceeds the barrier).

\section{What Level of Barrier to Use?}

In the slightly different context of designing stress tests, Jeffery \& Smith (2019: 47) suggest the following aphorisms:

- If something has happened before, it can happen again.

- If it has happened elsewhere, it can happen here.

- If it happens, when it happens it will happen faster than last time. 


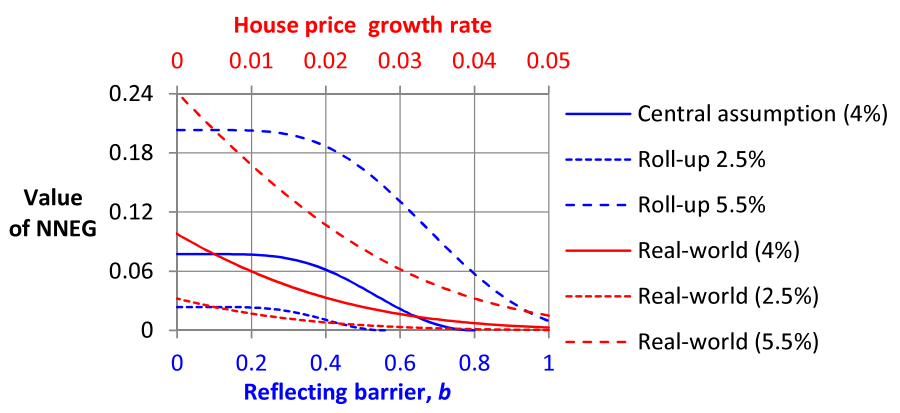

Figure 8. Barrier model versus "real-world" model: sensitivity to roll-up rate.

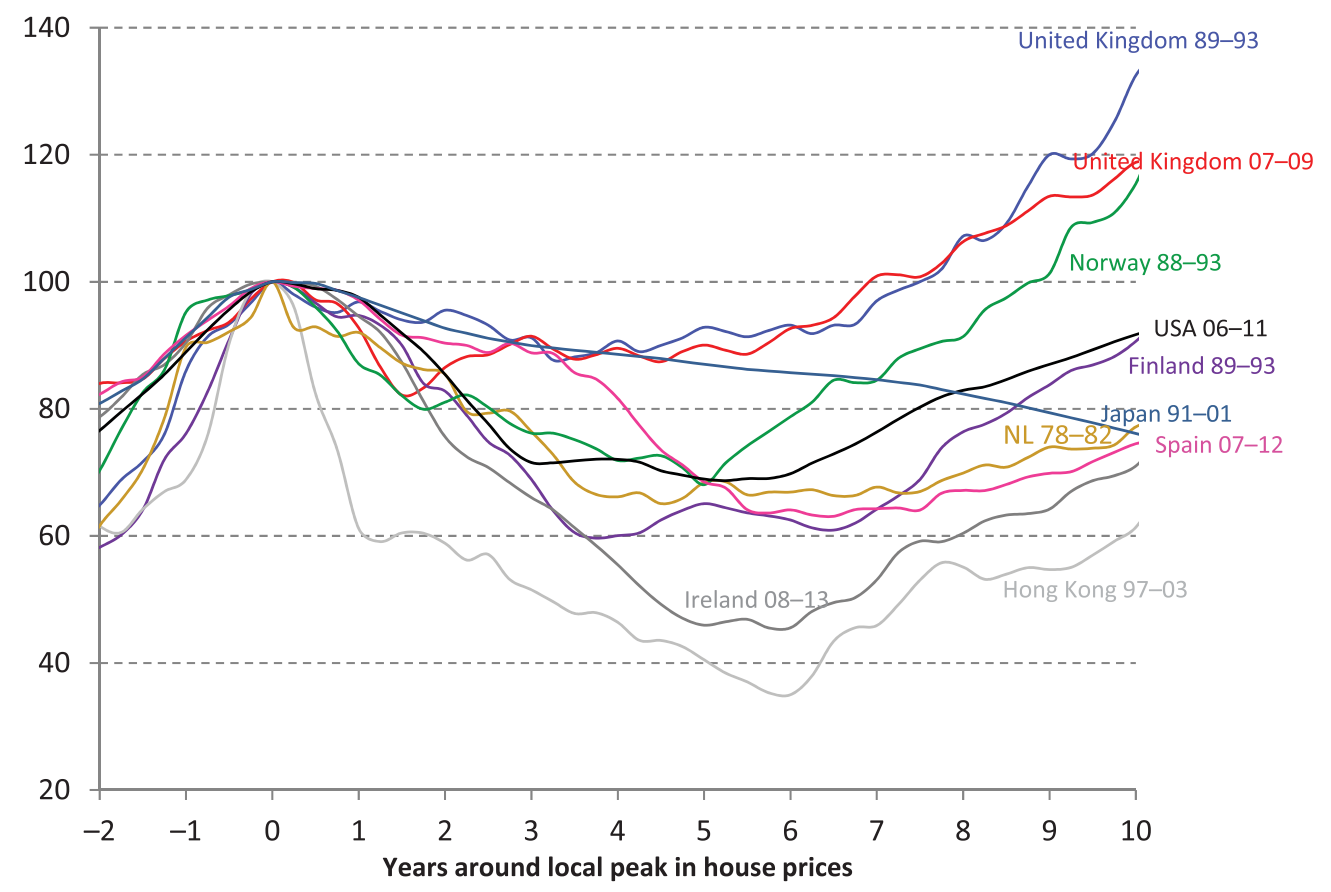

Figure 9. National house price indices around some of the largest falls in developed countries.

Data source: https://www.bis.org/statistics/index.htm. Numbers in country labels represent peak to trough years.

Whilst the purpose is slightly different, these aphorisms seem worthy of consideration when choosing the level of a reflecting barrier. The barrier is a hypothetical construct intended to represent either the prospect of future interventions or the distinctive nature of housing (and especially freehold land) assets, as discussed in sections 2 and 3 above; but a barrier which has actually been breached in the past may seem suspect. At the same time, my view is that the aphorisms are best regarded as guidelines rather than absolute rules.

Figure 9 shows the paths of indices of nominal house price indices from 2 years before to 10 years after a local peak, for selected countries and periods. These are not typical housing market downturns; the selection is intended to illustrate some of the worst recorded slumps in house prices in a range of countries with similar levels of economic development to the United Kingdom. The data are drawn from quarterly indices for nominal house prices collated by the Bank for International Settlements (BIS), re-based to 100 at the local peak.

I make the following observations in Figure 9 and related data. 
- The biggest falls in the United Kingdom have been modest compared to some other countries: peak-to-trough falls of $12 \%$ during $1989-93$ and $18 \%$ during $2007-09$, according to the BIS. It is also notable that these falls were followed by much stronger recoveries at 10 years than in any of the other countries.

- These modest reported falls represent national indices, but the prices of individual houses (some of which may fall much more) are the relevant factor for NNEG.

- The modest reported falls in the United Kingdom also mask considerable regional variation. The BIS figures are drawn from national indices published by the Office of National Statistics, which are based on Land Registry records of actual transaction prices for all purchases. Other organisations publish regional sub-indices, based on their proprietary samples of purchases funded by a mortgage. The Halifax House Price regional sub-indices not only recorded rises for Scotland and the north of England during the 1989-93 national slump, but also a largest regional fall of 35\% from peak to trough for East Anglia. During the 2007-09 slump, the largest regional fall was $26 \%$ for Greater London.

- Hong Kong 1997-2003 and Ireland 2008-2013 represent exceptionally severe slumps, where the peak-to-trough falls over about 6 years exceeded $50 \%$, but both with strong recoveries shortly thereafter.

- For scale reasons, Figure 9 does not show the full decline in Japan, where prices fell $46 \%$ over 18 years from the peak in 1991 to the trough in 2009. In Q2 2019, some 28 years after the peak, Japanese house prices were still 37\% below their 1991 level.

All things considered, I tentatively suggest a value of 0.5 as a suitable level for the reflecting barrier in a United Kingdom context. Note that this encompasses the exceptional long-term experience in Japan. I choose to elide the reported falls below 50\% in Ireland and Hong Kong, for three reasons. First, the periods below $-50 \%$ were brief, with strong recoveries shortly thereafter. Second, 0.5 is a convenient round figure. Third, the range of possible policy interventions in Ireland and Hong Kong may have been constrained by their inability or unwillingness to print their own currencies (Ireland uses the Euro, and the Hong Kong Dollar is pegged to the US Dollar). Others may prefer to use lower or higher values for the barrier, which are simple to implement in equation (2) in section 5 .

A barrier level of 0.5 would lead to values for NNEG always lower than Black '76, and often significantly lower, as can be seen in the graphs in section 6 . For a given level of barrier, the fractional reduction in the value of NNEG compared with Black'76 is smaller for higher roll-up rates, higher initial loan-to-value, and longer terms (all these increase the rolled-up loan and hence strike price, so the barrier becomes less significant). The barrier method's higher relative valuation of the more leveraged cases might be regarded as a reassuring feature.

\section{Discussion}

\subsection{Potential applications of the barrier model}

Possible uses of the barrier model include reserving, investment analysis, risk transfer and assessing trade-offs in public policy, as follows.

\subsubsection{Reserving}

Where permitted by regulation, the barrier model could be used for reserving. This is limited in some contexts, in particular, the PRA's Effective Value Test explicitly specifies the use of the Black ' 76 formula to value NNEG (see section 1.2), and so disregards the possibility of policy intervention. Acknowledging the possibility of policy intervention may be a delicate matter for a prudential regulator, for three reasons. First, most plausible forms of intervention involve monetary policy and fiscal policy, which are outside the purview of a prudential regulator. Second, 
a realistic official acknowledgement of the likelihood of intervention after a calamitous fall in prices may have the unwanted side effect of encouraging excessive risk-taking. Third, we are concerned with the prospects for intervention over a long timescale, well beyond that of any particular government or policy regime. I have no easy solutions to these difficulties, but nevertheless, I think that simply ignoring the prospect of policy intervention is unrealistic. In addition, even if policy intervention is to be ignored on principle, the alternative rationales in section 3 merit consideration.

\subsubsection{Investment analysis}

Where the State does not give any lead through reserving regulation, an investor may nevertheless have a view that if house prices fall a long way, some form of policy intervention is likely. The barrier model can assess how much difference this makes to share valuations.

\subsubsection{Risk transfer}

The barrier model can be used in pricing bulk risk transfers between parties who share the belief that some level of policy intervention is likely after a large fall in prices; or for product pricing, capital allocation, and other management purposes.

\subsubsection{Assessing trade-offs in public policy}

The current regulatory requirement that insurers must make allowance for NNEG using a model where much of the NNEG value derives from very extreme scenarios for house prices reduces the assessed value of insurers' assets. This implies that more assets are required to back liabilities (for NNEG writers, principally annuities), which in turn implies that annuity prices are higher than they would otherwise be. Without making a precommitment to intervene at any particular level of prices, policymakers may nevertheless wish annuities to be priced on a basis which excludes the possibility of house prices falling below a certain level. This is not a denial of the possibility that prices might fall to even lower levels; it is an expression of (reasonable) preferences about allocations over different future states of the world. Stated differently, it is a judgment that society prefers to deal with some extreme contingencies ex post, rather than by mandating that resources are set aside ex ante.

This trade-off between affordable annuity pricing and requiring insurers to reserve for very extreme scenarios is a social and political choice. In my view, it is not a decision that should be made solely by a prudential regulator. In debate about NNEG valuation, there seems to have been little explicit discussion of this trade-off, perhaps because it has been difficult to quantify. The barrier model provides one potential way of quantifying the trade-off. For example, we could investigate how much difference an assumed barrier at each of several different levels makes to insurers' costs of capital, and hence to annuity pricing.

\subsection{Effect of the barrier on volatility and the spot price}

The model in this paper treats intervention as an extraneous event which is superimposed on the price process, but not anticipated by the price process. This is most straightforwardly applicable in a scenario where the barrier represents a guarantee provided on a specific investment fund (e.g. Gerber \& Pafumi, 2000; Imai \& Boyle, 2001), which is not relevant to anyone other than investors in the fund, and so cannot affect the spot price. However, in this paper, the barrier is relevant to market participants in general. In this scenario, the model provides a mathematically tractable approach, but it may seem unrealistic in the following respects. 
(i) First, if market participants anticipate the intervention, we might expect volatility (or at least its downside component) to fall as the spot price approaches the barrier.

(ii) Second, if the value of a put option today is reduced by the prospect of intervention at the barrier, we might also expect today's spot price to be raised by the existence of the barrier.

On the first point, long-term volatility is normally estimated by scaling short-term volatility (i.e. $\sigma_{T}=\sigma \sqrt{T}$ ). Provided that the barrier has been well below the spot price throughout the observation period used to estimate volatility, the existence of the barrier far below the spot can reasonably be expected to have only a negligible effect on observed short-term volatility. Hence, scaling this should produce an estimate consistent with the volatility parameter as defined in the model.

On the second point, it turns out that this is not problematic, given the way we have expressed option prices in this paper. In all the examples in sections 4.1 and 6, the observed spot price was set to 1; so our barrier, all strikes and all option prices were expressed in a numeraire of the observed spot price. Suppose the spot price is $£ 100$ and a fully credible barrier is newly introduced at $£ 90$. We might expect the spot price to rise considerably, say to $£ 120$; but in the framework of this paper, we would then observe a barrier not at 0.9 but at 0.75 . The pricing formula still works if the numeraire is a spot price elevated by a universal barrier (as in the NNEG scenario, and in the derivation in Appendix A), rather than a spot price unaffected by a guarantee provided on a single fund (as in the Gerber \& Pafumi (2000) scenario).

This argument relies on the particular choice of the spot house price as our numeraire. If for any reason this is not done, then in the NNEG context, there are two further points that can be made. First, we are not contemplating the "introduction" of a barrier and consequent change in the observed spot price; the barrier has always been there, and so all our data on prices represent prices in the presence of the barrier. Second, the barrier is not at $90 \%$ of the spot price but at a much lower fraction, and so if its existence does raise the observed spot price (in a numeraire of $\mathfrak{E})$, the effect is likely to be small. In particular, it should be proportionally much smaller than the effect of the barrier on the $\mathfrak{E}$ value of a deep out-of-the-money put option, which is drastically reduced (or even made worthless, if the barrier is above the strike).

\subsection{More realistic barrier concepts and ESG models}

The concerns discussed in the previous section turned out on closer examination to be less serious than they first appeared. A more compelling criticism is that the fixed nature of the barrier (i.e. a fraction of the spot price $S$ today) for options of all terms is unrealistic. It seems unlikely that policymakers considering intervention at some distant future date will make their decisions by reference to today's price level. They are more likely to be concerned with how far and how fast prices have fallen from their recent levels at the time when intervention is being contemplated. So the barrier model fails to represent the (plausible) prospect of interventions where prices first rise substantially from today's levels and then fall. This is particularly relevant to NNEG, because the strike price increases for longer terms (i.e. a NNEG is evaluated by summing the product of option valuation and exit probability over all possible terms, with the longest terms having strike prices which may be well above the house price today).

For a more realistic barrier concept, the barrier for an option of term $T$ could be a fraction of the highest point on the price path between 0 and $T$ (i.e. a fraction of the high-water mark over the option term). Intuitively, the effect of such a barrier on the value of NNEG would be larger than in this paper. Unfortunately, a NNEG with a path-dependent barrier seems more difficult to value. NNEG values in this type of model would probably have to be valued by simulation, i.e. an Economic Scenario Generator (ESG) approach. With this approach, more complex models of intervention could be considered, depending not just on the magnitude of the fall in prices from an initial value or a high-water mark, but also on the rate of change (e.g. intervention occurs if prices have fallen more than $15 \%$ in one year, or $30 \%$ in three years). 
As an alternative to assuming intervention according to a particular rule or rules, an ESG model might allow indirectly for the effects of intervention in the structural form of the price process. This could explicitly model a change in volatility (and potentially also drift) when house price growth deviates significantly from its long-term mean. One reasonable model may be to assume that with increasing deviations of the rate of house price growth from its long-term trend, policymakers become increasingly likely to intervene. This could be represented by a mean-reverting model for house price growth, where the level of mean reversion is itself mean-reverting.

\subsection{Idiosyncratic property risk}

The NNEG is an option on an individual property, not a property index. An objection to the reflecting barrier model, or indeed to any model of policymaker intervention, is that interventions will be targeted at the general level of house prices, not individual properties. Plausible interventions may not preclude any particular property suffering idiosyncratic local effects (e.g. planning blight, lack of maintenance, flooding) which cause it to fall to a very low price. It is true that a barrier model cannot provide a literal representation of these very few cases. But there also seems no reason to think that the lower tail of an unrestricted geometric Brownian motion provides a literal representation of these very few cases.

\section{Conclusions}

This paper has modelled NNEG with a reflecting barrier under house prices. The primary rationale for the barrier is that it represents the prospect of policymaker intervention after a large fall in prices. Alternatively, the barrier can be viewed as a way of making allowance for the different nature of underlying housing (and particularly freehold land) assets in NNEG valuations, compared with the underlying equity assets in many other option valuations.

Realistic interventions cannot place a completely firm barrier at a particular level, and in this sense, the model may overstate the certainty and efficacy of the intervention. On the other hand, the model also understates the prospect of interventions where prices first rise substantially from today's levels and then fall, and it ignores the possibility that market participants' anticipation of intervention will change the price process (and in particular, the volatility near the barrier). In short, limits to the realism of the model are not difficult to find. Nevertheless, it may still represent an improvement on extant standard models. The latter make no allowance at all for intervention in a market where most voters hold most of their wealth, which seems to me very unrealistic, and naïve about political economy.

Although the NNEG valuation formula with a reflecting barrier may appear complicated compared with Black '76, the complication is algebraic rather than parametric: there is only a single extra parameter, the barrier level $b$. The value of the single parameter $b$ can be used as a shorthand for different strength of beliefs about the prospects for intervention, or about the different nature of housing assets compared with equity assets. Whilst the barrier feature is an artificial model of intervention, it is also easy to describe and explain, including for audiences who may not understand all the niceties of option pricing.

I have tentatively suggested a value of 0.5 for the level of the reflecting barrier as a fraction of today's spot price. This would lead to values for NNEG always lower than Black '76, and often significantly lower. For a given level of barrier, the fractional reduction in the value of NNEG compared with Black ' 76 is smaller for higher roll-up rates, higher initial loan-to-value, and longer terms. The barrier method's higher relative valuation of the more leveraged cases might be regarded as a reassuring feature.

Others may have different views on an appropriate level for the barrier, or disagree that we should use a barrier at all. If no barrier is used, this paper highlights that much of the resulting 
value of NNEG may derive not from poor scenarios where house prices merely stagnate or fall, but from extreme scenarios where they fall by $50 \%$ or more over the term of the NNEG.

Acknowledgements. I thank Alan Reed, Andrew Smith, Pradip Tapadar and Radu Tunaru for helpful comments on earlier drafts. Naturally, they do not necessarily agree with everything in the paper, and any errors and inadequacies remain my own.

\section{References}

Andreasen, J., Jensen, B. \& Poulsen, R. (1998). Eight valuation methods in financial mathematics: the Black-Scholes formula as an example. Mathematical Scientist, 23(1), 18-40.

Baxter, M. \& Rennie, A. (1996). Financial Calculus: An Introduction to Derivative Pricing. Cambridge University Press, Cambridge, UK.

Black, F. (1976). The pricing of commodity contracts. Journal of Financial Economics, 3, 167-179.

Buckner, D. \& Dowd, K. (2019). The Eumaeus guide to equity release valuation: restating the case for a market consistent approach. Available online at the address www.eumaeus.org [accessed 22-Sep-2019].

Carozzi, F., Hilber, C.A.L., \& Yu, X. (2020). On the economic impacts of mortgage credit expansion policies: evidence from help to buy, Available online at the address https://ideas.repec.org/p/cep/cepdps/dp1681.html [accessed 19-Apr-2020].

Chwieroth, J.M. \& Walter, A. (2019a). The financialization of mass wealth, banking crises and politics over the long run. European Journal of International Relations, 25, 1007-1034.

Chwieroth, J.M. \& Walter, A. (2019b). The Wealth Effect: How the Great Expectations of the Middle Class Have Changed the Politics of Banking Crises. Cambridge University Press, Cambridge, UK.

Chwieroth, J.M. \& Walter, A. (2019c). The wealth effect: the middle class and the changing politics of banking crises, Available online at the address https://voxeu.org/article/satisfying-great-expectations-middle-class [accessed 27-Dec2019].

Derman, E. \& Taleb, N.N. (2005). The illusion of dynamic replication. Quantitative Finance, 5(4), 323-326.

Dowd, K., Buckner, D., Blake, D. \& Fry, J. (2019). The valuation of no-negative-equity guarantees and equity release mortgages. Economics Letters, 184, 1-4.

Gerber, H.U. \& Pafumi, G. (2000). Pricing dynamic investment fund protection. North American Actuarial Journal, 4 (2), 28-37.

Hertrich, M. \& Veestraeten, D. (2013). Valuing stock options when prices are subject to a lower boundary: a correction. Journal of Futures Markets, 33, 889-890.

Hertrich, M. (2015). A cautionary note on the put-call parity under an asset pricing model with a lower reflecting barrier. Swiss Journal of Economics and Statistics, 151, 227-260.

Hertrich, M. \& Zimmermann, H. (2015). On the credibility of the Euro/Swiss Franc floor: a financial market perspective. Working paper at http://ssrn.com/abstract=2290997, [accessed 30-Sep-2019].

Hertrich, M. \& Zimmermann, H. (2017). On the credibility of the Euro/Swiss Franc floor: a financial market perspective. Journal of Money, Credit and Banking, 49, 567-578.

Heston, S.L., Loewenstein, M. \& Willard, G.A. (2007). Options and bubbles. Review of Financial Studies, 20, 359-390.

Hosty, G.M., Groves, S.J., Murray, C.A. \& Shah, M. (2008). Pricing and risk capital in the equity release market. British Actuarial Journal, 14, 41-109.

Imai, J. \& Boyle, P.P. (2001). Dynamic fund protection. North American Actuarial Journal, 5(2), 31-49.

Jeffery, T. \& Smith, A.D. (2019). Equity release mortgages: UK and Irish Experience. Available online at the address https://web.actuaries.ie/events/2019/02/equity-release-mortgages-irish-experience [accessed 22-Sep-2019].

Knoll, K., Schularick, M., \& Steger, T. (2017). No price like home: global house prices, 1870-2012. American Economic Review, 107, 331-353.

Skorokhod, A.V. (1961). Stochastic equations for diffusion processes in a bounded region. Theory of Probability and Its Applications, 6, 264-274.

Stiglitz, J.E. (2015). New theoretical perspectives on the distribution of income and wealth among individuals: Part IV: land and credit, NBER Working Paper 21192. Available online at the address http://www.nber.org/w21192 [accessed 2-Dec2019].

Thomas, R.G. (2018). No-negative-equity guarantees: Black-Scholes and its discontents, Available online at the address http://www.guythomas.org.uk/blog/?e=28 [accessed 29-Sep-2019].

Tunaru, R. \& Quaye, E. (2019). Equity release mortgages: a review of the no negative equity guarantee. Available online at the address www.actuaries.org.uk [accessed 29-Sep-2019].

Turnbull, C. (2019a). On the Actuarial Treatment of Equity Release Mortgages. Available online at the address https://craigturnbullfia.com/ [accessed 29-Sep-2019]. 
Turnbull, C. (2019b). On the Actuarial Treatment of Equity Release Mortgages -Part 2. Available online at the address https://craigturnbullfia.com/ [accessed 29-Sep-2019].

Turnbull, C. (2019c). On the Actuarial Treatment of Equity Release Mortgages -Part 3. Available online at the address https://craigturnbullfia.com/ [accessed 29-Sep-2019].

Turner, A. (2016). Between Debt and the Devil: Money, Credit and Fixing Global Finance. Princeton University Press, Princetion, NJ.

Veestraeten, D. (2004). The conditional probability density function for a reflected Brownian motion. Computational Economics, 24, 185-207.

Veestraeten, D. (2008). Valuing stock options when prices are subject to a lower boundary. Journal of Futures Markets, 28, 231-247.

Wilmott, P. (2009). Frequently Asked Questions in Quantitative Finance. John Wiley \& Sons Ltd, Chichester, UK.

\section{Appendix A. Derivation of the put option pricing formula}

We start from the observed spot price $S_{0}$, which is a price given the long-standing existence of the barrier. The derivation then makes use of two price processes: a process for the observed price $S_{t}$ in the presence of the barrier, and a process for the notional price $N_{t}$ of an asset with the same starting value $S_{0}$ and same drift and variance, but where the barrier has no effect.

We assume that the notional price follows a real-world price process of geometric Brownian motion, specified as usual by

$$
d N_{t}=\mu N_{t} d_{t}+\sigma N_{t} d W_{t}
$$

where $\mu$ is the drift, $\sigma$ is the diffusion and $d W_{t}$ is the increment of a standard Wiener process.

Assuming the underlying pays a continuous yield $q$, the risk-neutral process for the notional price is obtained by replacing the drift $\mu$ with $(r-q)$ :

$$
d N_{t}=(r-q) N_{t} d_{t}+\sigma N_{t} d W_{t}
$$

Now consider the reflecting barrier $b$, such that the price is reflected instantaneously at the barrier. Because of the barrier, the observed process will be

$$
S_{t}=N_{t} \cdot \max \left[1, \max _{0 \leq n \leq t}\left(\frac{b}{N_{t}}\right)\right]
$$

In words, the process $S_{t}$ is equal to $N_{t}$, if $N_{t}$ has never gone below the barrier; or an up-rated version of $N_{t}$ which "undoes" the maximum proportional deficit relative to the barrier, if it has. Figure A1 illustrates how it works, for one unfavourable simulation over 25 years.

Now rescale each of $N_{t}$ and $S_{t}$ by first dividing by the barrier (so the barrier becomes 1 ) and then taking logs (so the barrier becomes zero), to give $Y_{t}=\ln \left(N_{t} / b\right)$ and $Z_{t}=\ln \left(S_{t} / b\right)$.

$Z_{t}$ is then equivalent to " $Y_{t}$, but with a reflecting barrier introduced at zero". We call the process $Z_{t}$ "reflected geometric Brownian motion" (RGBM).

By a standard construction in the theory of stochastic processes, RGBM can be specified in a form analogous to equation (A.2) but with an extra $d L_{t}$ term to represent the reflection at zero, as follows:

$$
d Z_{t}=(r-q) Y_{t} d_{t}+\sigma Y_{t} d W_{t}+Y_{t} d L_{t}
$$

where the process $L_{t}$ is a "reflection function" as in Skorokhod (1961:266). $L_{t}$ starts from $L_{0}=0$ and increases whenever $Z_{t}$ hits the lower barrier of zero. $L_{t}$ keeps track of the cumulative amount of upward reflection. This reflection at the barrier is instantaneous and of infinitesimal magnitude. Hence, the observed process does not spend finite time on the barrier, and there are no jumps. Together, these features ensure that the no-arbitrage property is preserved; in other words, it is never possible to buy at the barrier for a certain profit with no risk.

The RGBM process as specified in equation (A.4) is a semimartingale, because it can be decomposed into a local martingale (the Wiener term) and two finite variation processes, the drift and 


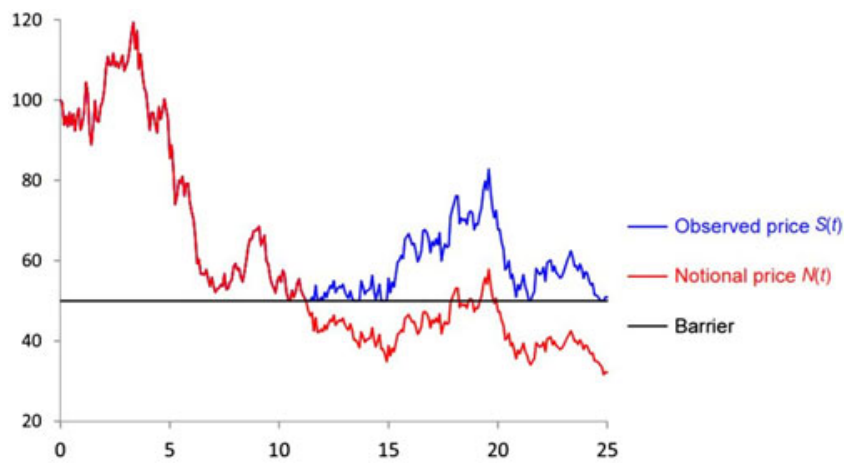

Figure A1. One simulation for $N_{t}$ and $S_{t}$.

the reflection. So we can apply Itô's lemma to equation (A.4) to obtain

$$
d \ln Z_{t}=\left(r-q-\frac{\sigma^{2}}{2}\right) d_{t}+\sigma d W_{t}+d L_{t}
$$

Conveniently, the density of the RGBM process $Z_{t}$ is known (Veestraeten, 2004), and hence also the transformed density for the observed price, $S_{t}=b \exp Z_{t}$. The following formula gives the risk-neutral probability of reaching an observed price $S_{T}$ at maturity, evaluated at time 0 when the spot price is $S_{0}$, with $b$ as a reflecting barrier (Hertrich, 2015: 235; or without the income, Veestraeten, 2008, also p235):

$$
\begin{aligned}
f\left(S_{T}\right) \equiv & f\left(S_{T} \mid S_{0}, r, q, \sigma, T, b\right) \\
= & \frac{\left\{\mathrm{e}^{-\frac{\ln \left(\frac{S_{T}}{S_{0}}\right)-\left.\left(r-q-\frac{\sigma^{2}}{2}\right) T\right|^{2}}{2 \sigma^{2} T}}+\mathrm{e}^{\frac{\ln \left(\frac{b}{S_{0}}\right)\left[2(r-q)-\sigma^{2}\right]}{\sigma^{2}}} \mathrm{e}^{\left.-\frac{\ln \left(\frac{S_{T} S_{0}}{b^{2}}\right)-\left.\left(r-q-\frac{\sigma^{2}}{2}\right) T\right|^{2}}{2 \sigma^{2} T}\right\}}\right.}{\sigma S_{T} \sqrt{2 \pi T}} \\
& -\frac{\left[2(r-q)-\sigma^{2}\right]}{S_{T} \sigma^{2}} \mathrm{e}^{\frac{\ln \left(\frac{S_{T}}{b}\right)\left[2(r-q)-\sigma^{2}\right]}{\sigma^{2}}} \\
& \cdot\left\{1-\Phi\left(\frac{\ln \left(\frac{S_{T} S_{0}}{b^{2}}\right)+\left(r-q-\frac{\sigma^{2}}{2}\right) T}{\sigma \sqrt{T}}\right)\right\}
\end{aligned}
$$

This reduces to the density of GBM for the case $b=0$, as expected.

The risk-neutral price of the put with the reflecting barrier can then be found by integrating the intrinsic value of the put over this risk-neutral density, that is, we integrate

$$
P_{B}(X)=e^{-r T} \int_{b}^{X}\left(X-S_{T}\right) f\left(S_{T}\right) d S_{T}
$$

to give the valuation formula in section 5 of the paper (except that the $S_{0}$ denoting the current spot price in the density in equation (A.6) has been elided to just $S$ for brevity in section 5).

The reader may wonder why after neutralising the drift in equation (A.2), we subsequently turned our attention to the reflecting barrier, but then did nothing to neutralise the interventions at the barrier. Is something missing? One way of understanding this is to note that the interventions represent a form of "hybrid return", neither fully risk-free nor fully stochastic. The incidence of the interventions if the price touches the barrier is guaranteed, but the quantum of 
the interventions over any given term is uncertain. Note also that because of the instantaneous and infinitesimal nature of the interventions, their effect cannot be hedged away. This explains why terms for the barrier remain in the risk-neutral valuation formula, rather than disappearing in the same way as the term for the (hedgeable) drift in the underlying.

\section{Sources}

Veestraeten (2008) derives the risk-neutral price for a call option on a an asset that pays no dividends with a reflecting barrier under the price. As an after-thought, he obtains a price for a put option from the standard put-call parity, but this is problematic (see Appendix B). Hertrich \& Veestraeten (2013) give the correct formula for the risk-neutral value of a put on a an asset that pays no dividends. Hertrich \& Zimmermann (2017) consider a put on an exchange rate; this version is the one directly adapted for the present paper. Hertrich (2015) gives a fuller account of the derivation, leading to the same formula but with the terms grouped in a slightly different way, and also gives a more technical discussion of the put-call parity issue than my intuitive treatment in Appendix B. The working paper Hertrich \& Zimmermann (2015) gives some of the necessary integrals.

\section{Appendix B. Put-call parity in the presence of a reflecting barrier}

The put option formula in the main text looks correct at the extremes and plausible everywhere in between. It was obtained by turning the handle on the usual risk-neutral pricing machinery. But if we do the same for a call option with barrier less than strike $(b<X)$, we obtain another plausible-looking formula:

$$
\begin{aligned}
C_{B}(X \mid S, r, q, \sigma, T, b) \\
\quad=S e^{-q T} \Phi\left(z_{1}\right)-X \mathrm{e}^{-r T} \Phi\left(z_{1}-\sigma \sqrt{T}\right) \\
\quad+\frac{1}{\theta}\left\{\begin{array}{l}
+S e^{-q T}\left(\frac{b}{S}\right)^{1+\theta} \Phi\left(z_{2}\right) \\
-X e^{-r T}\left(\frac{X}{b}\right)^{\theta-1} \Phi\left(z_{2}-\theta \sigma \sqrt{T}\right)
\end{array}\right\}
\end{aligned}
$$

Note that this is the Black' 76 formula for a call, plus the $1 / \theta$ term $^{11}$.

The difference of the risk-neutral values for call and put (equations (A.8) less (2)) is

$$
\begin{aligned}
= & S e^{-q T} \Phi\left(z_{3}\right)-X e^{-r T} \\
& +b e^{-r T}\left(1-\frac{1}{\theta}\right) \Phi\left(-z_{3}+\sigma \sqrt{T}\right) \\
& +\frac{1}{\theta}\left\{S e^{-q T}\left(\frac{b}{S}\right)^{1+\theta} \Phi\left(z_{4}\right)\right\}
\end{aligned}
$$

which we shall call the "risk-neutral put-call parity". The risk-neutral put-call parity can also be written as

$$
e^{-r T}\left\{\mathrm{E}^{Q}\left[S_{T}\right]-X\right\}
$$

where the $Q$-superscript indicates that the expectation is calculated using the risk-neutral density for RGBM as in equation (A.6). Note that under this density, $\mathrm{E}^{Q}\left[S_{T}\right]>S e^{(r-q) T}$, where the

11 This expression, and also equation (2) for the put in the main paper and their difference in equation (A.9), all look slightly different to those in Hertrich (2015), because he defines some of the $z$ variates differently in that paper. His $z_{3}$ is my $z_{2}$, and his $z_{4}$ is my $-z_{3}+\sigma \sqrt{ } T$. I am using the variates as defined in Hertrich \& Zimmerman (2017). Showing equivalence involves unpacking the $\theta$ term inside the argument of one of the normal distribution functions. 


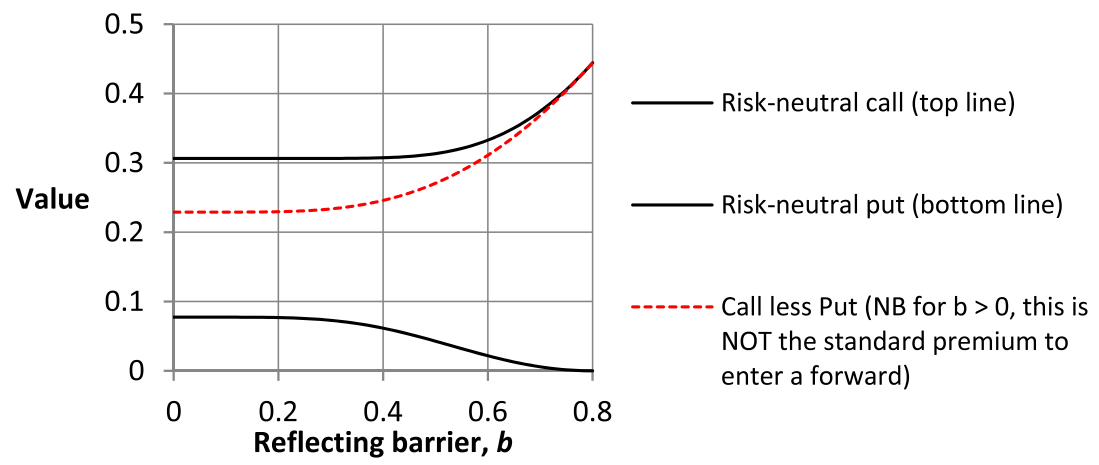

Figure A2. Risk-neutral call and put prices with a reflecting barrier.

latter corresponds to $\mathrm{E}\left[S_{T}\right]$ under the risk-neutral density for standard GBM. Hence, for the risk-neutral put-call parity in equation (A.10), the following is true:

(1) it is larger than the "standard put-call parity", that is premium to enter a forward to buy at strike $X$, which is

$$
e^{-r T}\left\{S e^{(r-q) T}-X\right\} \text { and }
$$

(2) it reduces to the standard put-call parity only for $b=0$.

In other words, in the presence of a reflecting barrier, standard put-call parity appears not to hold.

To put some numbers on this phenomenon, Figure A2 illustrates risk-neutral call and put prices and their difference for our central parameters as specified in section 4.1. Considering each extreme in Figure A2:

- At $b=0$ (i.e. no barrier) on the left-hand side, the risk-neutral call (top line) and risk-neutral put (bottom line) prices calculated using equations (A.8) and (2) are 0.306 and 0.077; these are the same as the Black '76 values calculated in section 4.1, as expected. The difference (middle dashed line) is 0.229 , which is the same as the premium paid to enter a forward with strike 0.8 , again as calculated in section 4.1 .

- At $b=0.8$ (i.e. barrier equal to the strike) on the right-hand side, the risk-neutral call and put prices calculated using equations (A.8) and (2) are 0.444 and 0.

- So the difference of the two risk-neutral option prices (0.444) in the presence of the barrier is larger than the premium to enter a forward (0.229). The latter is still calculated by the same formula, $\mathrm{e}^{-r T}\left[S e^{(r-q) T}-0.8 S\right]=0.229$, the same as in the $b=0$ case $^{12}$.

To understand what is happening, we need to think about the different effects that the interventions have on forward pricing and risk-neutral option pricing.

In section 4.2, I said that intuitively, the formula for the price of a forward should not be affected by the barrier, which moves spot and forward in the same way. But how does this intuition reconcile with the "higher than standard" risk-neutral expectation $\mathrm{E}^{Q}\left[S_{T}\right]>S e^{(r-q) T}$ as mentioned just after equation (A.10)? Does this imply the forward should trade higher than the standard forward price, reflecting the expected "hybrid return" from interventions? No, because if it does trade higher, there is a static arbitrage (short one unit of "expensive" forward, long one unit of "cheap"

12 Note that whilst the algebraic formula for a pricing a forward is unchanged by introduction of the barrier, this does not mean that the sterling cost of the premium is unchanged. Recall that all our formulae and graphs use the observed spot price as the numeraire. Introducing a barrier where none existed before will raise the observed spot price $\left(S^{\prime}>S\right.$ as discussed in section 4.2). So the premium to enter a forward using pounds sterling as the numeraire is higher than in the absence of the barrier. 
underlying) by which a trader can capture the excess with certainty. The excess should, therefore, be eliminated by this static arbitrage. In the presence of interventions, the standard arbitrage pricing mechanism for a forward still works, so the standard pricing formula continues to apply.

For options, the effect of the interventions is different. Suppose we try to synthesise the payoff from a put option in the normal way, i.e. by maintaining a portfolio consisting of short a suitable fraction of the underlying asset, long a suitable quantum of a risk-free bond. Now consider the reflecting barrier. On any occasion when the spot price touches the barrier, an intervention will occur, and because the interventions are instantaneous, we cannot adjust the hedge. So intuitively, both the short position in the asset and the long position in the bond should be smaller, in anticipation of the unhedgeable interventions.

The crucial difference between forward pricing and option pricing is that a forward can be hedged statically, and there is an arbitrage which can capture (and therefore eliminate) any anticipated effect of interventions embedded in the forward price. But option replication requires dynamic hedging, and the hedging strategy cannot respond to the instantaneous reflections at the barrier. Forward pricing eliminates the interventions; risk-neutral option pricing must allow for them. Using risk-neutral option prices (for puts and calls together) is, therefore, inconsistent with the standard put-call parity.

In these circumstances, what option prices should we use? Recall that as well as (normally) being mutually implicative with the standard put-call parity, risk-neutral option pricing also has another attractive interpretation: it represents the "cost of manufacture" of the option payoff via dynamic replication. So we can still adopt this interpretation of a risk-neutral price for either of put or call; but if we do so for both, we shall be inconsistent with forward pricing. Which should we choose, put or call? There are several reasons for preferring the risk-neutral price of the put:

(a) For NNEG, the "cost of manufacture" interpretation is of interest for the put, but not of interest for the call. Although we cannot actually manufacture a NNEG via dynamic replication, because houses cannot readily be sold short, it may be reasonable to use the hypothetical cost of doing so as the price of NNEG (and current PRA regulation encourages this).

(b) The risk-neutral put formula gives a sensible answer at $b=0$ (where it gives the Black '76 price) and $b=X$ (where it gives 0 ). Everywhere in between, it is a bit less than the bull put spread, which is consistent with intuition.

(c) On the other hand, the risk-neutral call formula gives a sensible answer at $b=0$ (where it gives the Black ' 76 price), and gives progressively higher prices as $b$ rises (as shown by the top line in Figure A2). This is consistent with the intuition that anticipating the (unhedgeable) "hybrid return" from interventions makes a call more costly to replicate. But if we adopt this price for the call and then apply standard put-call parity to infer the put, we get a positive price for the put for $b=X$, which seems clearly wrong.

(d) More generally, a put is a bounded claim. Any sensible price must be in the range (0, $X$ $-b$ ) because it can never be worth more than its maximum payoff paid today (assuming positive interest rates). Our formula gives a single price in this range. On the other hand, a call is an unbounded claim, and so can feasibly take a wider range of values.

In the light of these points, a pragmatic solution is to adopt the risk-neutral price for the put, and note the need for caution about inferring the price of a call. Standard put-call parity implies one price for the call; risk-neutral pricing (or equivalently, the "risk-neutral put-call parity" in equation (A.9)) implies a different (higher) price. Happily, we do not normally require or observe call prices in the context of NNEG. Nobody can synthesise a bought put by a combination of bought call and forward sale at strike $X$, because the required instruments are simply not traded. Hence, the consideration of put-call parity is more a point of theoretical interest, rather than a need to be consistent with any observed market prices. 
More technically, the failure of risk-neutral put and call prices together to ensure put-call parity arises because although the no-arbitrage property is preserved with the reflecting barrier (so a riskneutral measure exists, and option replication still works), the martingale property is lost. The RGBM process is a sub-martingale under the risk-neutral measure, whereas a martingale must be both a sub- and super-martingale. The high risk-neutral price for the call arises because the intervention creates a nonnegative bubble in the risk-neutralised price of the underlying, so there is also a bubble in the price of the call (Heston et al., 2007). "Nonnegative bubble" has a technical meaning here, but the ordinary meaning gives the gist.

An intuitive reaction of some readers to this discussion may be that the standard put-call parity is a model-free concept, which option prices ought to satisfy irrespective of the assumed price process of the underlying asset. However, I believe that this intuition breaks down where the price process includes some "hybrid return" occurring only at a discrete barrier, neither fully risk-free nor fully stochastic. I do not deny that the standard put-call parity is an important concept (and hence this appendix). But I do deny that using risk-neutral prices for both puts and calls can be consistent with forward pricing, in the presence of a reflecting barrier as defined in this paper. As Heston et al. (2007) succinctly note "One can choose either put-call parity or risk-neutral option pricing [for both puts and calls], but not both.”

\section{Appendix C. Replication strategy}

If continuous costless trading in the underlying asset is possible, we can replicate the payoff of any option which depends only on the terminal value of the asset by maintaining a suitable hedge portfolio (e.g. Baxter \& Rennie, 1996: 95). Although we cannot do this in practice for NNEG (because houses cannot readily be sold short), it is interesting that the theoretical hedging strategy turns out to be simpler than the casual inspection of the put formula in equation (2) might suggest.

The hedging strategy for a put option involves being short a suitable fraction of the underlying asset and long a suitable quantum of risk-free bond. By continuously adjusting this hedge, we are sure to end up with the "right" positions in asset and bond to offset the payoffs of the option. For example, if the put option expires in the money, the hedging scheme ensures that we end up short exactly 1 unit of the asset (offsetting the 1 unit of the asset which will be put to us when the option is exercised), and long the bond in an amount equal to the strike price (offsetting the cash we are obliged to pay when the option is exercised).

To find the required fractional short position, we need to find the partial derivative of the put option price in equation (2) with respect to the asset price $S$. The derivative includes four normal distribution functions and eight normal density functions, but remarkably the latter all cancel. Writing $V$ for the option price, the required short position in the asset is given by

$$
\frac{\partial V}{\partial S}=e^{-q T}\left\{\Phi\left(z_{1}\right)-\Phi\left(z_{3}\right)+\left(\frac{b}{S}\right)^{1+\theta}\left[\Phi\left(z_{4}\right)-\Phi\left(z_{2}\right)\right]\right\}
$$

and the required quantum of the long position in the bond is given by equations (2) less (A.12).

For $b=0$, this gives the same hedge fraction and bond investment as for Black'76, as expected. As the barrier increases from zero, the magnitude of both the hedge fraction and bond investment decline, but the latter declines faster, so the price of the hedge portfolio (and hence the option) declines. When $b$ reaches $X$, both the hedge fraction and bond investment reach zero, again as expected.

\section{Appendix D. Reconciliation to the price of an investment guarantee}

Gerber \& Pafumi (2000) and Imai \& Boyle (2001) price a guarantee on an investment fund. The guarantee is dynamic in the sense that whenever the fund falls to the guarantee level, an 
infinitesimal amount of money is added to the fund to prevent it falling below the guarantee level, and the observed fund value accumulates thereafter with the benefit of that addition. The guarantee is European in the sense that the accumulated proceeds of the fund can only be accessed at the maturity date. This combination of dynamic construction and European payoff corresponds to the main features of the options in the present paper. So intuitively, we should be able to reconcile our option formula to their guarantee formula. One way of thinking about this is as follows.

The guarantee implies that the investor receives the fund with the accumulated benefit of the interventions, but no strike price is payable at the end of the term, and the investor receives the benefit of the interventions irrespective of the level where the fund ends up. This payoff can be expressed as a combination of a bought put and a written call with the presence of the barrier, both with at-the-money strikes. Note that the two strikes cancel, giving no net payment by the investor at the end of the term, as appropriate for the guarantee. We then need to compare this payoff with that from the same option position without the presence of the barrier. The difference in the value of the two payoffs gives the price of the guarantee:

$$
C_{B}(S)-P_{B}(S)-C(S)-P(S)
$$

and expanding this using equations (2) and (A.8) with $q=0$ (i.e. no income distributed by the fund) then yields equation 2.11 in Gerber \& Pafumi (2000), as expected.

Cite this article: Thomas RG (2021). Valuation of no-negative-equity guarantees with a lower reflecting barrier. Annals of Actuarial Science 15, 115-143. https://doi.org/10.1017/S1748499520000172 